\title{
Interaction between effector and memory cd8+ t cells enhances melanoma adoptive immunotherapy
}

\author{
Amanda Contreras*, Andrew Tatar, Siddhartha Sen, Justin Meyers, Prakrithi Srinand, David Mahvi, Clifford Cho \\ From 30th Annual Meeting and Associated Programs of the Society for Immunotherapy of Cancer (SITC 2015) \\ National Harbor, MD, USA. 4-8 November 2015
}

\begin{abstract}
Introduction
Our laboratory has previously demonstrated that adoptive cell transfer (ACT) of melanoma-specific memory $\mathrm{T}$ cells $\left(\mathrm{T}_{\mathrm{M}}\right)$ results in a more potent local and systemic $T$ cell response than ACT with melanoma-specific effector $T$ cells $\left(T_{E}\right)$. However, we have also seen that $T_{M}$ are not more cytotoxic than $\mathrm{T}_{\mathrm{E}}$ in vitro. We hypothesized that a combination of $\mathrm{T}_{\mathrm{E}+\mathrm{M}} \mathrm{ACT}$ would have an additive effect compared to $\mathrm{T}_{\mathrm{E}}$ and $\mathrm{T}_{\mathrm{M}} \mathrm{ACT}$ alone.
\end{abstract}

\section{Methods}

C57BL/6 mice were inoculated with subcutaneous injections of B16F10 melanoma cells transfected to express low levels of the lymphocytic choriomeningitis virus (LCMV) peptide GP33 (B16GP33). GP33-specific $\mathrm{T}_{\mathrm{E}}$, $\mathrm{T}_{\mathrm{M}}$, or $\mathrm{T}_{\mathrm{E}+\mathrm{M}}$ ACT was administered seven days after tumor inoculation. Cultured GP33-specific $\mathrm{T}_{\mathrm{E}}, \mathrm{T}_{\mathrm{M}}$, or $\mathrm{T}_{\mathrm{E}+\mathrm{M}}$ were stimulated with GP33 or co-cultured with B16GP33 cells.

\section{Results}

Combinatorial $\mathrm{T}_{\mathrm{E}+\mathrm{M}}$ ACT resulted in more potent suppression of in vivo B16GP33 melanoma growth compared to $\mathrm{T}_{\mathrm{M}}$ or $\mathrm{T}_{\mathrm{E}} \mathrm{ACT}$ alone. $\mathrm{T}_{\mathrm{E}+\mathrm{M}} \mathrm{ACT}$ resulted in slightly higher populations of total CD8+ TILs compared with $\mathrm{T}_{\mathrm{M}}$ ACT. $\mathrm{T}_{\mathrm{E}+\mathrm{M}}$ ACT did not result in higher numbers of exogenously-derived transferred $\mathrm{T}$ cells; rather, combination ACT resulted in a profound induction of endogenous TILs. In addition, combination ACT induced the most potent systemic $\mathrm{T}$ cell response to tumor antigen. In vitro, $\mathrm{T}_{\mathrm{E}}$ and $\mathrm{T}_{\mathrm{M}}$ were comparable in their ability to inhibit of melanoma growth, but $\mathrm{T}_{\mathrm{E}+\mathrm{M}}$ was synergistic. This synergy was reproduced by applying conditioned media derived from activated $\mathrm{T}_{M}$ to co-culture wells containing $\mathrm{T}_{\mathrm{E}}$. The addition of neutralizing IL-2 antibody negated this effect. $T_{E}$ were more effective at inhibiting melanoma cell growth at early time points, but the strength of this inhibition diminished over time. In contrast, $T_{M}$ became more effective at inhibiting melanoma growth over time.

\section{Conclusions}

Overall, these data suggest that a synergistic interaction between $T_{E}$ and $T_{M}$ may promote combinatorial ACT's superior anti-tumor efficacy. Combinatorial ACT's strong endogenous $\mathrm{T}$ cell infiltration and systemic response indicates that the combination's synergistic effect is enhancing the host's immune system. Our in vitro results suggest that cytokines released by stimulated $\mathrm{T}_{\mathrm{M}}$ may augment the local cytotoxicity of $\mathrm{T}_{\mathrm{E}}$ and that the temporal differences in killing may enhance the combination's ability to inhibit tumor growth. Further investigations will be performed to understand the cellular and molecular mechanisms responsible for this clinically promising observation.

Published: 4 November 2015

doi:10.1186/2051-1426-3-S2-P8

Cite this article as: Contreras et al.: Interaction between effector and memory cd8+ $\mathrm{t}$ cells enhances melanoma adoptive immunotherapy. Journal for ImmunoTherapy of Cancer 2015 3(Suppl 2):P8. 